\title{
Casca de soja em dietas para ovinos ${ }^{1}$
}

\section{José Walter dos Santos ${ }^{2}$, Luciano da Silva Cabral ${ }^{3}$, Joanis Tilemahos Zervoudakis ${ }^{3}$, Alexandre Lima de Souza ${ }^{4}$, Joadil Gonçalves de Abreu ${ }^{3}$, Maristela de Oliveira Bauer ${ }^{3}$}

\author{
${ }^{1}$ Financiado pela FAPEMAT e pelo CNPq \\ 2 Escola Agrotécnica da São Gabriel da Cachoeira - AM. \\ ${ }^{3}$ Faculdade de Agronomia e Medicina Veterinária - UFMT, Av. Fernando Corrêa da Costa, s/n, Coxipó, Cuiabá - MT, CEP: $78060-900$. \\ ${ }^{4}$ ICEN - CUR/UFMT, Rondonópolis - MT.
}

RESUMO - Objetivou-se avaliar a utilização de quatro níveis de casca de soja $(0 ; 8,0 ; 16,0$ ou 24,0\%) em substituição ao fubá de milho $(0,25,50$ e $75 \%)$ em dietas para ovinos em confinamento. Avaliaram-se o consumo e a digestibilidade dos nutrientes, o desempenho animal, a conversão alimentar e os custos com a dieta. Vinte cordeiros da raça Santa Inês com peso vivo médio inicial de 32,96 kg foram distribuídos em delineamento inteiramente casualizado com quatro tratamentos e cinco repetições. A dieta foi composta de $50 \%$ de volumoso (50\% de silagem de milho e $50 \%$ de cana-de-açúcar picada) e 50\% de concentrado. Os concentrados foram compostos de fubá de milho, farelo de soja, mistura mineral e uréia, de modo que o fubá de milho foi gradativamente substituído pela casca de soja. Os animais foram mantidos em baias individuais com comedouro e bebedouro. Não foram observados efeitos dos níveis de casca de soja da dieta sobre o consumo de nutrientes, exceto o de FDN, que aumentou linearmente de acordo com o nível de casca de soja na dieta. Os níveis de casca de soja não influenciaram a digestibilidade dos nutrientes, o ganho de peso $(0,215 \mathrm{~kg} / \mathrm{animal} / \mathrm{dia})$ e a conversão alimentar dos animais $(6,20 \mathrm{~kg} \mathrm{MS} / \mathrm{kg}$ peso ganho $)$. O aumento do nível de casca de soja de 0 e $75 \%$ na dieta reduziu os gastos com alimentação e aumentou a margem bruta de R\$10,89 para R\$ 18,63 por animal. A substituição de até $75 \%$ do fubá de milho por casca de soja na dieta não afeta o desempenho de ovinos em terminação em confinamento.

Palavras-chave: conversão alimentar, consumo, cordeiros, digestibilidade, ganho de peso

\section{Soybean hulls in sheep diets}

\begin{abstract}
The objective was to evaluate the use of four levels of soybean hulls (0.0, 8.0, 16.0 and 24.0\%) to replace the corn meal $(0.0,25,50$ and $75 \%)$ in the diet of sheep in feedlot. Performance, nutrient digestibilities and feeding costs were evaluated. Twenty Santa Inez breed lambs with $32.96 \mathrm{~kg} \mathrm{BW}$ were distributed to a completely randomized design with four diets and five replications. The diet was composed of 50\% forage (50\% of corn silage and $50 \%$ of sugar cane) and $50 \%$ concentrate. The concentrates were composed of corn meal, soybean meal, mineral mix and urea, so corn meal was gradually replaced by soybean hulls. No effect was observed in the levels of soybean hulls of diet on feed intake of nutrients, except for NDF, which linearly increased according to soybean hulls level in the diet. Soybean hulls levels did not affect digestibility of nutrients, weight gain $(0.215 \mathrm{~kg} /$ anim.day) and feed conversion ratio of the animals $(6.20 \mathrm{~kg} \mathrm{DM} / \mathrm{kg}$ weight gain). Increasing of soybean hulls levels in the diet reduced feeding cost and increased the gross margin from R $\$ 10.89$ to $\mathrm{R} \$ 18.63$ per animal in the 0 and $75 \%$ of replacement levels, respectively. The replacement of up to $75 \%$ of corn meal by soybean hulls in the diet does not affect performance of sheep finished in feedlot.
\end{abstract}

Key Words: digestibility, feed:gain ratio, consumption, lambs, weight gain

\section{Introdução}

O Brasil possui rebanho ovino de aproximadamente 17,5 milhões de cabeças, sendo grande maioria produzida em pastagem. Entretanto, a produção de carne ovina nestas condições não atende a demanda do mercado consumidor nacional.
Tradicionalmente, nos trópicos, a produção de ruminantes em pastagem sofre os efeitos da sazonalidade de produção forrageira, limitando a produção e produtividade dos rebanhos brasileiros. Desta forma, estratégias de alimentação devem ser implementadas para contornar os problemas decorrentes da distribuição irregular na oferta de forragem. 
Nesse sentido, há necessidade de se intensificar a produção por meio de terminação de cordeiros em regime de confinamento, objetivando, dessa forma, a produção mais rápida de carne de qualidade, principalmente porque 90\% da carne ovina consumida no Brasil têm origem em outros países, tais como Uruguai, Paraguai, Argentina e Chile (ANUALPEC, 2005).

O fubá de milho é o concentrado energético mais utilizado na formulação de dietas para os animais. Contudo, como é utilizado na alimentação humana e apresenta grande variação de preço ao longo do ano, que aumentou recentemente pelo uso crescente na produção de etanol americano, torna-se necessária a realização de pesquisas que avaliem alimentos alternativos. A utilização de resíduos da agricultura na alimentação animal pode ser uma alternativa nutricional e economicamente viável.

O conteúdo em nutrientes da casca de soja pode variar conforme o processo de industrialização dos grãos da soja para a produção de óleo. A casca de soja, de acordo com Zambom et al. (2001), constitui $2 \%$ do total do grão, no entanto, esse percentual pode variar de 0 a $3 \%$.

Nutricionalmente, Restle et al. (2004) relataram que a casca de soja, por apresentar elevado teor de FDN, foi inicialmente estudada como uma opção para substituição da fração volumoso da dieta de ruminantes. Entretanto, por apresentar elevada digestibilidade da FDN, proporcionar elevada produção de ácidos graxos voláteis no rúmen, em razão da excelente fermentabilidade da fibra no rúmen (Bach et al., 1999) e dos benefícios decorrentes da digestão da fibra da dieta total sobre o $\mathrm{pH}$ ruminal (Ludden et al., 1995; Gomes, 1998), a casca de soja se destaca quanto ao seu potencial de uso na alimentação de ruminantes em substituição aos grãos de cereais.

O estado de Mato Grosso é o maior produtor de soja do País, conseqüentemente o maior produtor de casca de soja. Desta forma, sua utilização na alimentação de ruminantes apresenta grande potencial, tanto por reduzir os impactos ambientais como pela possibilidade de sua transformação em alimentos nobres para o homem (carne e leite), além de seu baixo custo na suplementação animal.

Assim, este trabalho foi realizado com o objetivo de avaliar níveis de substituição do fubá de milho por casca de soja em dietas para ovinos em terminação em confinamento.

\section{Material e Métodos}

Este trabalho foi realizado no período de 6 de novembro a 15 de dezembro de 2005, no Setor de Ovinocultura da Fazenda Experimental da Universidade Federal de Mato Grosso (UFMT), localizada no município de Santo Antônio do Leverger, Mato Grosso, nas coordenadas de $15^{\circ} 47^{\prime} 05^{\prime \prime}$ Sul e $56^{\circ} 04^{\prime}$ Oeste, com altitude de $140 \mathrm{~m}$.

As dietas foram compostas de $50 \%$ de volumoso (25\% cana-de-açúcar in natura picada e $25 \%$ de silagem de milho) e $50 \%$ de concentrado, formulados para serem isoprotéicos, contendo $20 \%$ de $\mathrm{PB}$, compostos por fubá de milho, farelo de soja, uréia, mistura mineral e casca de soja (CS), nas proporções de $0,25,50$ e $75 \%$ de substituição ao fubá de milho (Tabela 1), que corresponderam aos níveis de $0,8,16$ e $24 \%$ da casca de soja na matéria seca da dieta. As dietas foram formuladas para conter aproximadamente $13,50 \%$ de PB, de acordo com o NRC (1985).

Foram avaliados o consumo e a digestibilidade dos nutrientes, o desempenho e a conversão alimentar, assim como os custos relativos à alimentação de ovinos recebendo dietas contendo diferentes níveis de casca de soja.

Utilizaram-se 20 animais da raça Santa Inês, machos nãocastrados, com 170 dias de idade e peso vivo inicial em jejum (PVIJ) de 32,96 $\pm 1,58 \mathrm{~kg}$. Inicialmente, os animais foram casqueados, vacinados, pesados, identificados e tratados contra endoparasitos. Posteriormente, os animais foram distribuídos em delineamento inteiramente casualizado com quatro tratamentos e cinco repetições e mantidos em baias individuais com piso suspenso e ripado, dotadas de comedouro e bebedouro, e área de $1,5 \mathrm{~m}^{2}$.

O experimento teve duração de 50 dias: 10 dias para adaptação dos animais e 40 para as avaliações. Os animais foram pesados no início e no final do experimento, após jejum de sólidos por 16 horas. O consumo foi quantificado pela diferença entre a oferta e as sobras e a excreção fecal foi estimada pelo uso da fibra indigestível insolúvel em detergente neutro (FDNi), por meio de amostras de fezes coletadas diretamente da ampola retal dos animais, diariamente, nos sete dias finais do experimento, em intervalo de 26 horas.

A dieta foi fornecida duas vezes ao dia: a primeira oferta às $7 \mathrm{~h} 30 \mathrm{e}$ a segunda às $15 \mathrm{~h} 30$. Diariamente, as sobras foram monitoradas de modo que seu percentual fosse próximo a $10 \%$ do fornecido, com base na matéria natural.

Tabela 1 - Composição dos ingredientes dos concentrados

\begin{tabular}{lcccc}
\hline Ingrediente & \multicolumn{4}{c}{ Nível de casca de soja na dieta (\%) } \\
\cline { 2 - 5 } & 0 & 8,0 & 16,0 & 24,0 \\
\hline Fubá de milho & 66,00 & 50,00 & 32,50 & 16,60 \\
Farelo de soja & 28,00 & 28,00 & 28,00 & 28,00 \\
Casca de soja & 0,0 & 16,20 & 32,5 & 50,0 \\
Mistura mineral & 5,0 & 5,0 & 5,0 & 5,0 \\
(NAVIFOS) $^{\circledR}$ & & & & \\
Uréia & 1,00 & 0,80 & 0,50 & 0,40 \\
\hline
\end{tabular}


Tabela 2 - Composição química dos ingredientes das dietas experimentais

\begin{tabular}{|c|c|c|c|c|c|c|c|}
\hline Ingrediente & \multicolumn{7}{|c|}{ Composição química (\%) MS } \\
\hline Fubá de milho & 91,00 & 7,42 & 3,90 & 1,50 & 87,18 & 16,79 & 98,50 \\
\hline Casca de soja & 93,00 & 12,13 & 2,42 & 4,47 & 80,98 & 67,04 & 95,53 \\
\hline Silagem de milho & 29,22 & 7,47 & 1,92 & 5,74 & 91,77 & 42,34 & 94,26 \\
\hline Cana-de-açúcar & 27,07 & 2,73 & 3,56 & 2,02 & 87,47 & 49,17 & 97,98 \\
\hline
\end{tabular}

MM - matéria mineral; CT - carboidratos totais.

Tabela 3 - Composição química das dietas experimentais

\begin{tabular}{lrrrr}
\hline \multirow{2}{*}{ Nutriente } & \multicolumn{4}{c}{ Nível de casca de soja na dieta (\%) } \\
\cline { 2 - 5 } & \multicolumn{1}{c}{0} & \multicolumn{1}{c}{8,0} & 16,0 & \multicolumn{1}{c}{24,0} \\
\hline PB & 14,29 & 13,26 & 13,62 & 13,81 \\
EE & 2,50 & 2,19 & 2,19 & 2,07 \\
MM & 3,42 & 3,35 & 4,11 & 4,50 \\
MO & 93,58 & 86,65 & 92,39 & 92,80 \\
CT & 83,02 & 76,71 & 79,29 & 78,22 \\
FDN & 31,46 & 35,55 & 39,54 & 44,07 \\
\hline
\end{tabular}

Durante o período de coletas (sete dias finais), as amostras dos ingredientes volumosos, das rações, das sobras e das fezes foram coletadas, pesadas, identificadas de acordo com o animal e o tratamento, embaladas em sacos plásticos e acondicionadas em freezer para posterior análise. Posteriormente, foram encaminhadas ao Laboratório de Nutrição Animal da FAMEV, onde foram descongeladas e homogeneizadas para obtenção das amostras compostas. As amostras dos volumosos e concentrados e das sobras e fezes foram pré-secas em estufas de ventilação forçada a $65^{\circ} \mathrm{C}$, por 72 horas. Em seguida, foram processadas em moinho tipo Willey utilizando peneiras com porosidade de $1 \mathrm{~mm}$ (Silva \& Queiroz, 2002).

Nestas amostras foram realizadas as análises para determinação da matéria seca (MS), proteína bruta (PB), extrato etéreo (EE) e matéria mineral (MM) de acordo com Silva e Queiroz (2002); da fibra insolúvel em detergente neutro (FDN), segundo Van Soest et al. (1991); e os carboidratos totais (CT) foram obtidos de acordo com Sniffen et al. (1992), por meio da equação CT $=100-(\mathrm{PB}$ $+\mathrm{MM}+\mathrm{EE})($ Tabelas 2 e 3 ).

Na determinação da FDNi, as amostras dos alimentos e das sobras e fezes foram acondicionadas em sacos tipo náilon e incubadas no rúmen de um bovino macho castrado, mestiço Caracu/Nelore, pesando $350 \mathrm{~kg}$ de peso vivo (PV), com fístula ruminal, durante 144 horas.

Após o período de incubação, as amostras foram retiradas e processadas segundo metodologia descrita por
Berchielli et al. (2000). O material remanescente da incubação foi submetido à análise para determinação da FDNi, segundo Cochran et al. (1986), a qual foi utilizada para cálculo dos coeficientes de digestibilidade de matéria seca (MS), proteína bruta (PB), extrato etéreo (EE), matéria orgânica (MO), carboidratos totais (CT), fibra insolúvel em detergente neutro (FDN) e nutrientes digestíveis totais (NDT).

O teor de nutrientes digestíveis totais (NDT), em \%, foi calculado de acordo com Brody (1945), pela seguinte equação NDT $(\%)=\mathrm{PBD}+\mathrm{CTD}+\mathrm{EED} * 2,25$, em que $\mathrm{CDT}=$ carboidratos digestíveis totais $; \mathrm{PBD}=$ proteína bruta digestível; e EED = extrato etéreo digestível.

Os dados foram submetidos a análises de variância por meio do software estatístico SAEG (2001):

$$
\mathrm{Y}_{\mathrm{ij}}=\mu+\mathrm{N}_{\mathrm{i}}+\mathrm{e}_{\mathrm{ij}}
$$

em que: $Y_{i j}=$ valor da variável consumo, digestibilidade dos nutrientes ou ganho de peso referente ao animal i e à dieta $\mathrm{j} ; \mu=$ constante geral; $\mathrm{N}_{\mathrm{i}}=$ efeito referente ao n-ésimo nível de inclusão de casca de soja; $\mathrm{e}_{\mathrm{ij}}=$ erro aleatório, pressuposto normalmente e independentemente distribuído com média zero e variância comum.

\section{Resultados e Discussão}

Não foram observados efeitos dos níveis de casca de soja sobre o consumo dos nutrientes (Tabela 4), com exceção da FDN, que aumentou $(\mathrm{P}<0,05) 3,704 \mathrm{~g} / \mathrm{animal} / \mathrm{dia}$ a cada $1 \%$ de casca de soja na dieta. Da mesma forma, o consumo de FDN expresso em porcentagem do PV e em $\mathrm{g} / \mathrm{kg}$ do $\mathrm{PV}$ foram linearmente aumentados $(\mathrm{P}<0,05)$.

De acordo com a proposição de Mertens (1987), quando o consumo de FDN é superior a $12,0 \mathrm{~g} / \mathrm{kg}$ de PV, o consumo de alimentos é regulado pela repleção ruminal. Desta forma, seria esperado menor consumo de matéria seca para os animais alimentados com a dietas com maiores teores de casca de soja. Entretanto, considerando que a FDN dos subprodutos, como a casca de soja, não apresenta a mesma tendência no TGI que a FDN dos 
Tabela 4 - Consumos de matéria seca (kg/animal/dia, \% PV, g/kg/PV $\left.{ }^{0,75}\right)$, matéria orgânica (MO), proteína bruta (PB), extrato etéreo (EE), carboidratos totais (CT) e fibra insolúvel em detergente neutro (kg/animal/dia e \% PV)

\begin{tabular}{|c|c|c|c|c|c|c|c|c|}
\hline \multirow[t]{2}{*}{ Variável } & \multicolumn{4}{|c|}{ Nível de casca de soja na dieta (\%) } & \multirow[t]{2}{*}{ ER } & \multirow[t]{2}{*}{ CV (\%) } & \multirow[t]{2}{*}{$\mathrm{R}^{2}$} & \multirow[t]{2}{*}{$\mathrm{P}$} \\
\hline & 0 & 8,0 & 16,0 & 24,0 & & & & \\
\hline CMS (kg/animal/dia) & 1,20 & 1,34 & 1,30 & 1,23 & $\hat{\mathrm{Y}}=1,27$ & 11,88 & - & - \\
\hline CMS (g/kg PV) & 3,25 & 3,56 & 3,48 & 3,32 & $\hat{\mathrm{Y}}=3,40$ & 10,17 & - & - \\
\hline Matéria seca (g/kg PV) & 80,17 & 88,22 & 86,12 & 81,77 & $\hat{\mathrm{Y}}=84,07$ & 8,54 & - & - \\
\hline MO (kg/animal/dia) & 1,13 & 1,26 & 1,21 & 1,14 & $\hat{\mathrm{Y}}=1,18$ & 11,82 & - & - \\
\hline PB (kg/animal/dia) & 0,16 & 0,18 & 0,18 & 0,16 & $\hat{\mathrm{Y}}=0,17$ & 13,17 & - & - \\
\hline EE (kg/animal/dia) & 0,03 & 0,02 & 0,02 & 0,02 & $\hat{\mathrm{Y}}=0,02$ & 12,69 & - & - \\
\hline CT (kg/animal/dia) & 0,91 & 1,02 & 0,93 & 0,91 & $\hat{\mathrm{Y}}=0,99$ & 11,67 & - & - \\
\hline FDN (kg/animal/dia) & 0,37 & 0,45 & 0,51 & 0,56 & 1 & 10,84 & 0,97 & 0,0002 \\
\hline FDN $(\% \mathrm{PV})$ & 1,01 & 1,23 & 1,42 & 1,52 & 2 & 7,74 & 0,97 & 0,0000 \\
\hline FDN (g/kg PV) & 10,09 & 12,26 & 14,24 & 15,23 & 3 & 7,74 & 0,97 & 0,0000 \\
\hline
\end{tabular}

ER: ${ }^{1} \hat{Y}=0,3836+0,003704 x ;{ }^{2} \hat{Y}=1,04+0,01042 x ;{ }^{3} \hat{Y}=10,40+0,10425 X$.

volumosos, em taxa de digestão ruminal e taxa de passagem, não houve efeito do teor de FDN na dieta sobre o consumo de matéria seca.

O mesmo comportamento foi verificado por Oliveira et al. (2007) com vacas em lactação, em que o aumento dos níveis de casca de soja não afetou o consumo de matéria seca, mas aumentou o percentual de FDN nas dietas, semelhante ao verificado por outros autores (Ipharraguerre \& Clark, 2003).

Vazques \& Smith (2000) sugerem que, a partir dessas observações, a utilização exclusiva do teor de FDN para a predição do consumo de MS é inadequada, pois os teores de lignina, a composição dos carboidratos estruturais, a taxa e a extensão da digestão da parede celular, o tamanho e a densidade de partículas devem ser considerados na avaliação do consumo de MS, sobretudo quando são utilizadas diferentes fontes de FDN na dieta.

De acordo com Ipharraguerre e Clark (2003), a manutenção do consumo de matéria seca com a utilização de casca de soja em dietas para ruminantes pode ser atribuída ao efeito positivo da elevada taxa de digestão da FDN, do reduzido tamanho das partículas e da elevada capacidade de hidratação da casca de soja, proporcionando elevação na taxa de passagem da FDN pelo trato gastrointestinal e, conseqüentemente, da ingestão de MS.

Oliveira et al. (2007) avaliaram dietas com $50 \%$ de substituição do fubá de milho pela casca de soja e também não verificaram diferenças no coeficiente de digestibilidade dos nutrientes em vacas leiteiras. De modo semelhante, Mendes et al. (2005) substituíram 60\% do milho do concentrado por casca de soja e também não observaram efeitos sobre o consumo e a digestibilidade das dietas. Segundo estes autores, a casca de soja apresenta maior digestibilidade de sua fração fibrosa, o que favorece sua eficiente utilização pelos animais ruminantes.

Considerando que a FDN é uma fração dos alimentos de lenta e incompleta digestão no trato gastrintestinal (TGI), tem sido negativamente correlacionada ao valor nutritivo dos alimentos (Mertens, 1996). Desta forma, dietas com elevado teor de FDN apresentam, de modo geral, reduzida digestão dos nutrientes, notadamente dos carboidratos. Neste trabalho, embora o teor de FDN tenha sido incrementado na dieta com os níveis de casca de soja, cujos teores variaram de 31,46 a 44,07\% na MS da dieta, para as dietas com zero e $24 \%$ de casca de soja, respectivamente, não houve efeito de redução da digestibilidade aparente dos nutrientes (Tabela 5). Esse fato reforça a diferença entre a taxa de digestão e a digestibilidade da FDN da casca de soja e os volumosos convencionais.

Não houve efeito $(\mathrm{P}>0,05)$ dos níveis de casca de soja sobre o ganho médio diário e conversão alimentar, que apresentaram valores médios de 0,215 g/animal/dia e 6,20, respectivamente (Tabela 6).

Thiago et al. (2000) avaliaram o efeito da substituição de milho por casca de soja em dietas para bovinos de corte em confinamento e verificaram melhoria no ganho de peso dos animais, assim como redução de $44 \%$ no custo da alimentação. Os autores afirmaram que a substituição do milho pela casca de soja melhora o ambiente ruminal reduzindo os efeitos negativos decorrentes do consumo excessivo de amido, proporcionando elevada digestão dos nutrientes, adequado crescimento microbiano e elevada produção de ácidos graxos voláteis. Nesse sentido, Mendes et al. (2006) observaram que a substituição parcial do milho pela 
Tabela 5 - Digestibilidade dos nutrientes das dietas experimentais

\begin{tabular}{|c|c|c|c|c|c|c|}
\hline \multirow[t]{2}{*}{ Variável } & \multicolumn{4}{|c|}{ Nível de casca de soja na dieta (\%) } & \multirow[t]{2}{*}{ ER } & \multirow[t]{2}{*}{$\mathrm{CV}(\%)$} \\
\hline & 0 & 8,0 & 16,0 & 24,0 & & \\
\hline MS & 70,85 & 66,72 & 66,05 & 70,16 & $\hat{\mathrm{Y}}=68,45$ & 3,52 \\
\hline $\mathrm{PB}$ & 89,55 & 87,06 & 85,23 & 88,90 & $\hat{\mathrm{Y}}=87,69$ & 2,2 \\
\hline $\mathrm{EE}$ & 75,42 & 63,33 & 54,58 & 75,50 & $\hat{\mathrm{Y}}=67,21$ & 15,14 \\
\hline FDN & 47,10 & 39,82 & 43,56 & 54,98 & $\hat{\mathrm{Y}}=46,37$ & 13,95 \\
\hline NDT & 75,07 & 69,70 & 68,97 & 73,15 & $\hat{\mathrm{Y}}=71,72$ & 4,02 \\
\hline
\end{tabular}

Tabela 6 - Peso vivo inicial em jejum (PVMIJ), peso vivo final em jejum (PVMFJ), ganho de peso total (GPT), ganho médio diário (GMD), conversão alimentar (CA), custos e receita obtidos com as dietas experimentais

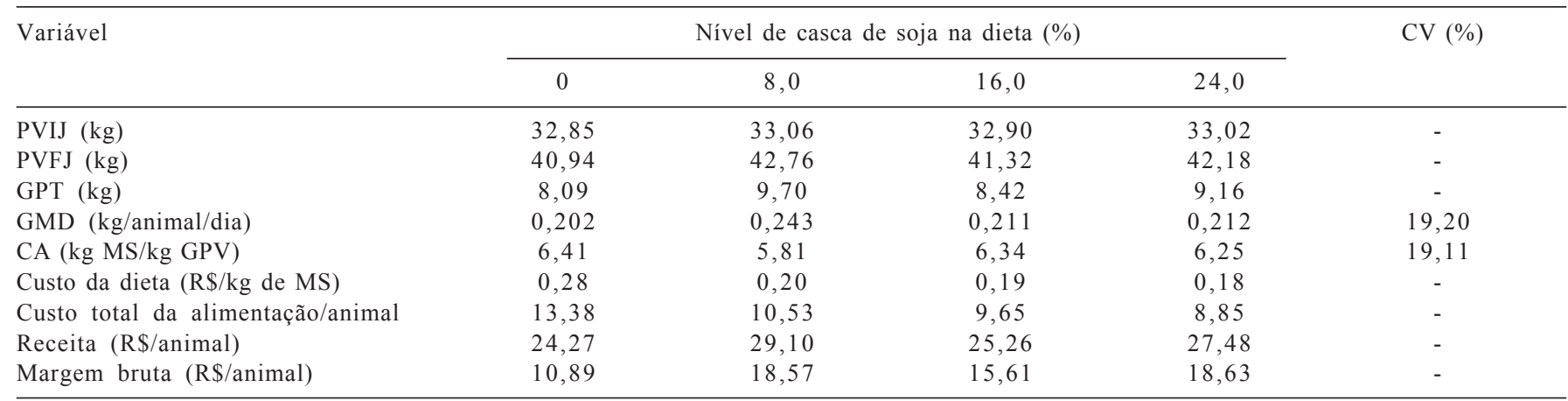

Custo dos ingredientes: silagem de milho ( $\mathrm{R} \$ 75,00 / \mathrm{t}$ matéria natutal), cana-de-açúcar ( $\mathrm{R} \$ 25,00 / \mathrm{t}$ matéria natural); milho ( $\mathrm{R} \%$ 0,34/kg); farelo de soja $(\mathrm{R} \$ 0,48 / \mathrm{kg})$; casca de soja $(\mathrm{R} \$ 0,25 / \mathrm{kg})$.

casca de soja melhorou a produção e eficiência microbiana, aumentando a contribuição da proteína microbiana que chegou ao duodeno.

Os resultados encontrados por Thiago et al. (2000) corroboram a possibilidade de se substituir em até $75 \%$ o milho pela casca de soja, sem que ocorra redução no desempenho dos animais, conforme verificado neste trabalho.

Restle et al. (2004) acrescentaram que a utilização da casca de soja na alimentação de bovinos de corte, além do aspecto econômico, pode trazer benefícios na eficiência de utilização dos alimentos pelo animal, visto que os grãos de cereais comumente utilizados (milho e sorgo) apresentam elevado teor de amido e podem provocar efeitos associativos negativos, promovendo redução da digestibilidade da fração fibrosa da dieta (Van Soest, 1994).

Esses autores sugeriram que a melhora no desempenho dos animais com a adição de casca de soja, o que não foi notado neste trabalho, deve estar relacionada a um efeito associativo positivo no rúmen, melhorando o aproveitamento da dieta, principalmente dos alimentos volumosos, que contribuem, em média, com mais de $40 \%$ da matéria seca da dieta oferecida. Fahey \& Berger (1993), citados por Restle et al. (2004), afirmam que o principal fator que afeta a digestão dos carboidratos estruturais é a adição de carboidratos solúveis, por meio de alimentos concentrados, que provocam alterações no trato digestivo e na cinética do processo digestivo, como a taxa de digestão, taxa de passagem das partículas, $\mathrm{pH}$ ruminal e natureza da população microbiana.

Semelhante ao observado neste trabalho, Galati et al. (2003) avaliaram o desempenho de novilhos Nelore em confinamento alimentados com $60 \%$ de silagem de milho e concentrado contendo casca de soja em substituição ao milho (70\%) e também não observaram diferença significativa para o ganho médio diário.

Ezequiel et al. (2006) verificaram que a substituição de $70 \%$ do milho moído por casca de soja não afetou o consumo de matéria seca, o ganho de peso, a conversão e eficiência alimentar e o rendimento de carcaça de novilhos Nelore confinados.

Entretanto, quando avaliado o aspecto econômico neste estudo, o uso da casca de soja promoveu redução significa- 
tiva do custo da dieta, proporcionando redução nos gastos com a alimentação por animal de $\mathrm{R} \$ 13,38$ para $\mathrm{R} \$ 10,53$, $\mathrm{R} \$ 9,65$ e $\mathrm{R} \$ 8,85$ nos níveis zero, 8,16 e 24\% na dieta, que corresponderam aos níveis de 0, 25, 50 e 75\% de substituição do fubá de milho pela casca de soja no concentrado.

Desta forma, o aumento dos níveis de casca de soja na dieta proporcionou aumento na margem bruta por animal em 70, 43 e 71\%, respectivamente, para os níveis de 8,16 e $24 \%$ de casca de soja na dieta. Na média, o uso da casca de soja na dieta promoveu aumento na margem bruta de $62 \%$ em comparação ao tratamento controle (apenas fubá de milho).

Esses resultados são relativos aos preços dos ingredientes verificados no estado de Mato Grosso, que, por ser um grande produtor de soja, disponibiliza a casca de soja em preço relativamente baixo em comparação a outras regiões do País. Desta forma, provavelmente em outras regiões do País, onde não há a produção da soja, com a compra da casca de soja de outros estados, o preço do ingrediente seja relativamente superior ao verificado no Mato Grosso, muitas vezes semelhante ao preço do milho. Nesta circunstância, o uso da casca de soja deve ser visto para dietas com elevado teor de grãos, no sentido de reduzir a incidência de distúrbios digestivos decorrentes do teor de amido da dieta.

\section{Conclusões}

A inclusão de casca de soja em substituição ao fubá de milho não influencia o consumo e a digestibilidade dos nutrientes, o ganho de peso diário e a conversão alimentar. A casca de soja pode substituir o fubá de milho em até $75 \%$ no concentrado, ou seja, ser acrescentada até o nível de $24 \%$ na dieta de ovinos. A formulação de dietas com casca de soja para ovinos em confinamento reduz os gastos com alimentação e promove aumento da margem bruta em comparação à dieta formulada apenas com milho como ingrediente energético.

\section{Literatura Citada}

ANUAlPEC. Anuário da pecuária Brasileira. São Paulo: FNP consultoria e Comércio, 2005. p.249-251.

BACH, A.; YOON, I.K.; STERN, M.D. et al. Effects of type of carbohydrate supplementation to lush pasture on microbial fermentation in continuous culture. Journal of Dairy Science, v.82, p.153-160, 1999 .

BERCHIELlE, T.T.; ANDRADE, P.; FURLAN, C.L. Avaliação de indicadores internos em ensaios de digestibilidade. Revista Brasileira de Zootecnia, v.29, n.3, p.830-833, 2000.

BRODY, S. Bioenergetics and growth with special reference to the efficiency complex in domestic animals. New York: Reinhold Publishing Corporation, 1945. 1023p.
COCHRAN, R.C.; ADAMS, D.C.; WALLACE, J.D. et al. Predicting digestibility of different diets with internal markers: evaluation of four potential markers. Journal of Animal Science, v.63, n.5, p.1476-1483, 1986.

EZEQUIEL, J.M.B.; GALATI, R.L.; MENDES, A.R. et al. Desempenho e características de carcaça de bovinos Nelore em confinamento alimentados com bagaço de cana-de-açúcar e diferentes fontes energéticas. Revista Brasileira de Zootecnia, v.35, n.5, p.2050-2057, 2006.

IPHARREGUERRE, I.R.; CLARK, J.H. Review: soyhulls for dairy cows. Journal of Dairy Science, v.86, n.4, p.1052-1073, 2003.

GALATI, R.L.; EZEQUIEL, J.M.B.; SILVA, O.G.C. et a1. Desempenho e características da carcaça de novilhos Nelore alimentados com dietas contendo casca de soja ou farelo de gérmen de milho substituindo parcialmente o milho. In: REUNIÃO ANUAL DA SOCIEDADE BRASILEIRA DE ZOOTECNIA, 40., 2003, Santa Maria. Anais... Santa Maria: Sociedade Brasileira de Zootecnia, 2003. (CD-ROM).

GOMES, I.P.O. Substituição do milho pela casca de soja em dietas com diferentes proporções de volumoso:concentrado para bovinos em confinamento. Jaboticabal: Universidade Estadual Paulista, 1998. 84p. Tese (Doutorado em Zootecnia) - Universidade Estadual Paulista, 1998.

LUDDEN, P.A.; CECAVA, M.J.; HENDRIX, K.S. The value of soybean hulls as a replacement for corn in beef cattle diets formulated with or without added fat. Journal of Animal Science, v.73, p.2706-2711, 1995.

MENDES, A.R.; EZEQUIEL, J.M.B.; GALATI, R.L. et al. Consumo e digestibilidade total e parcial de dietas utilizando farelo de girassol e três fontes de energia em novilhos confinados. Revista Brasileira de Zootecnia, v.34, n.2, p.679-691, 2005.

MENDES, A.R.; EZEQUIEL, J.M.B.; GALATI, R.L. et al. Cinética digestiva e eficiência de síntese de proteína microbiana em novilhos alimentados com farelo de girassol e diferentes fontes energéticas. Revista Brasileira de Zootecnia, v.35, n.1, p.264-274, 2006.

MERTENS, D.R. Predicting intake and digestibility using mathematical models of ruminal function. Journal of Animal Science, v. 64, n. 5 , p.1548-1558, 1987

MERTENS, D.R. Using fiber and carbohydrate analyses to formulate dairy rations. In: INFORMATIONAL CONFERENCE WITH DAIRY AND FORAGES INDUSTRIES, 1996, Wisconsin. Proceedings... Wisconsin: 1996. p.81-92.

NATIONAL RESEARCH COUNCIL - NRC. Nutrient requeriments of sheep. 6.rev.ed. Washington, D.C.: 1985. 112p.

OLIVEIRA, A.S; CAMPOS, J.M.S.; VALADARES FILHO, S.C. et al. Substituição do milho por casca de café ou de soja em dietas para vacas leiteiras: consumo, digestibilidade dos nutrientes, produção e composição do leite. Revista Brasileira de Zootecnia, v.36, n.4, p.1172-1182, 2007 (sup1.).

RESTLE, J.; FATURI, C.; FILHO, D.C.A. et al. Substituição do grão de sorgo por casca de soja na dieta de novilhos terminados em confinamento. Revista Brasileira de Zootecnia, v.33, n.4, p.1009-1015, 2004.

UNIVERSIDADE FEDERAL DE VIÇOSA - UFV. SAEG - Sistema de análises estatísticas e genéticas. Viçosa, MG: UFV, 2001. $301 \mathrm{p}$.

SILVA, D.J.; QUEIROZ, A.C. Análise de alimentos: métodos químicos e biológicos. 3.ed. Viçosa, MG: Editora UFV, 2002. 235p

SNIFFEN, C.J.; O'CONNOR, D.J.; van SOEST, P.J. et al. A net carbohydrate and protein system for evaluating cattle diets: carbohydrate and protein availability. Journal of Animal Science, v.70, n.12, p.3562-3577, 1992

THIAGO, L.R.L.S.; SILVA, J.M.; FEIJÓ, G.L.D. et al. Substituição do milho pelo sorgo ou casca de soja em dietas para engorda de bovinos em confinamento. In: REUNIÃO ANUAL DA SOCIEDADE BRASILEIRA DE ZOOTECNIA, 37., 2000 , Viçosa, MG. Anais... Viçosa, MG: 2000. (CD-ROM). 
Van SOEST, P.J.; ROBERTSON, J.B.; LEWIS, B.A. Methods for dietary fiber, neutral detergent fiber, and nonstarch polyssacarides in relation to animal nutrition. Journal of Dairy Science, v.74, n.10, p.3583-3597, 1991

Van SOEST, P.J. Nutritional ecology of the ruminant. 2.ed. Ithaca: Cornell University Press, 1994. 476p.
VASQUEZ, O.P.; SMITH, T.R. Factors affecting pastures intake and total dry matter intake in grazing dairy cows. Journal of Dairy Science, v.83, n.10, p.2301-2309, 2000.

ZAMBOM, M.A.; SANTOS, G.T.; MODESTO, E.C. Valor nutricional da casca do grão de soja, farelo de soja e milho moído e farelo de trigo para bovinos. Acta Scientiarum, v.23, n.4, p.937-943, 2001. 